\title{
CHARCAS REIVINDICADA: HISTORIA LOCAL Y DISCURSO CRIOLLO EN LAS NOTICIAS POLÍTICAS DE PEDRO RAMÍREZ DEL ÁGUILA
}

\author{
Pilar Latasa \\ Universidad de Navarra
}

El primero de enero 1639, Pedro Ramírez del Águila firmaba sus conocidas Noticias políticas, cuyo título completo era Noticias políticas de Indias y relación descriptiva de la ciudad de La Plata, metrópoli de la provincia de los Charcas y Nuevo Reino de Toledo en las Occidentales de gran imperio del Perú. Lo hacía por encargo del entonces arzobispo de Charcas, Francisco de Borja, quien cumplía de este modo con lo dispuesto en la real cédula de 1635 acerca de recabar nuevas informaciones de los territorios indianos para que el cronista mayor de Indias, Tomás Tamayo de Vargas, redactara una Historia general eclesiástica, en la que debían recogerse también los acontecimientos más destacados de la historia secular, tales como «las conquistas, hazañas, gobiernos y lo demás que es adorno y noticia más señalada de lo sagrado» ${ }^{1}$. Aunque la elaboración del Teatro eclesiástico fue finalmente encomendada a Gil González Dávila², quien, según hemos podido comprobar, no utilizó la

1 Ramírez del Águila, Noticias políticas, pp. 5-7.

2 El cronista Gil González Dávila (1570-1658) publicó entre 1649-1655 su Teatro eclesiástico de la primitiva iglesia de las Indias, en dos volúmenes. La obra, que realiza un recorrido por la Iglesia del Nuevo Mundo, ha sido reeditada recientemente por J. Paniagua Pérez y M. I.Viforcos Marinas. Su autor aprovechó los materiales documentales que no llegó a utilizar Tamayo de Vargas (1588-1641).Ver Cuesta Domingo, 2007, pp. 135-136.

Esteve Barba ya confirmó que para elaborar la obra González Dávila había utilizado la documentación generada como consecuencia de la cédula de1635 y otra posterior de 
relación de Ramírez del Águila ${ }^{3}$, el contenido de las Noticias se ajusta a lo solicitado en la real cédula de $1635^{4}$.

El manuscrito que actualmente se conserva en la Indiana University es el que Pedro Ramírez del Águila entregó al arzobispo Borja a comienzos de $1639^{5}$. Es de suponer que este lo remitió a su vez a la corte. El largo proceso de «descubrimiento» de la obra ha sido estudiado con detalle por Josep M. Barnadas ${ }^{6}$. Baste recordar aquí que no se editó hasta 1978, cuando el diplomático boliviano, Jaime Urioste Arana, transcribió y publicó el manuscrito de forma incompleta ${ }^{7}$. Sin embargo, una publicación en la que se

1648. Según este autor, dicha orden motivó también la redacción de las relaciones de Diego de Córdoba Salinas sobre la diócesis de Lima y de Vasco de Contreras y Velarde sobre la del Cuzco. Esteve Barba, 1992, p. 136.

${ }^{3}$ En el cotejo de la parte del Teatro eclesiástico dedicada a Charcas con las Noticias hemos podido apreciar diferencias notables. Tal vez la más significativa sea que González Dávila recoge el establecimiento por parte del obispo Ramírez de Vergara de cuatro capellanías de 500 pesos en la capilla de Guadalupe de la catedral.Ver González Dávila, 2001, p. 168. Sin embargo, Ramírez del Águila, que fue precisamente uno de los beneficiarios de esta fundación, afirma refiriéndose a la capilla: «déjola dotada de buenas rentas para dos capellanes [...] a cada capellán señaló setecientos pesos de renta». Más adelante señala que «dejó instituida capilla y capellanes, que no han tenido efecto más de en cuanto a una capellanía -que fue precisamente la suya-, por la disipación y saco que hubo de sus criados en sus expolios y recámara que, como quien quedó por albacea y administrador de ellos, lo puedo testificar». Ramírez del Águila, Noticias políticas, pp. 145 y 167.

La capilla ha sido estudiada por Mesa y Gisbert, 1972. Nuestro autor la describe con detalle en la primera noticia de la tercera digresión: Ramírez del Águila, Noticias políticas, p. 145.

${ }^{4}$ En 1648 se volvieron a pedir informes. Por ejemplo, se solicitaron al obispado de Santa Cruz de la Sierra «para acabar de perfeccionar la obra que está haciendo [Gil González Dávila, cronista mayor de Castilla e Indias] del primero y segundo tomo del Teatro eclesiástico de las Iglesias del Perú y Nueva España, con las ciertas y particulares noticias que conviene de las vidas de los arzobispos y obispos de ellas, y cosas memorables de sus sedes». Carta del obispo de Santa Cruz.Valle de Mizque, 20.01.1651. Archivo General de Indias, en adelante: AGI, Charcas 139.

${ }^{5}$ Ramírez del Águila, Noticias políticas, p. 186.

${ }^{6}$ Barnadas, 2003, pp. 16-20.

7 Se trata de siete anexos: Memorial al rey de los procuradores de La Plata. Madrid, 17.03.1609; Autos de la división del obispado de la ciudad de La Plata en tres obispados. 17.01.1609; Bula de Gregorio y Real Cédula de Felipe III designando el obispado de La Paz como tribunal de apelación del arzobispado de La Plata. 1610; Ordenanzas del virrey Francisco de Borja para el bien de los indios y buen orden de los corregidores. Lima, 26.01.1619; Ordenanzas del virrey marqués de Cañete para el remedio de los excesos de los corregidores de naturales. 
introduzcan los anexos que incluyó el autor y se realice una edición crítica y un estudio histórico del texto está todavía pendiente ${ }^{8}$. A pesar del olvido, se trata de una obra de gran valor. Pedro Ramírez del Águila la redactó consciente de que estaba destinada a fines histórico-políticos "no solo...para histórica curiosidad -decía haberla escrito- sino para que su majestad [...] y su Real Consejo de las Indias penetren y se hagan dueños del estado de las cosas de esta ciudad y provincias, para la buena dirección en el gobierno de ellas» ${ }^{9}$. De hecho, las Noticias políticas son una fuente esencial para la historia de Charcas en el siglo XVII.

\section{Charcas, UNA NUEVA PATRIA}

Pedro Ramírez del Águila, que había nacido en 1581 en Archidona (Málaga), viajó a América con tan solo catorce años, formando parte del séquito del prelado extremeño Alonso Ramírez de Vergara, que había sido promovido a la archidiócesis de Charcas en $1595^{10}$. La primera parte de su estancia en La Plata estuvo estrechamente vinculada, como es lógico, con este personaje de quien, a la edad de 20 años, recibió las órdenes menores. Fallecido su protector, se trasladó a Lima, donde estudió bachiller de Cánones en la Universidad de San Marcos como colegial de San Felipe ${ }^{11}$. Poco después, por las sedes vacantes de Lima (1606-1608) y La Plata (16021611), tuvo que desplazarse a Chile para ser ordenado sacerdote ${ }^{12}$.

Lima 21.07.1594; Memoria de unos capítulos puestos a cierto gobernador por sus indios; Constituciones sinodales del arzobispado de la ciudad de La Plata hechas y ordenadas por Hernando Arias de Ugarte, arzobispo de la ciudad, 1620.

8 Actualmente dirigimos una tesis doctoral que tiene este objetivo.

9 Ramírez del Águila, Noticias políticas, p. 11.

10 Ha estudiado el personaje y su paso a América, basándose exclusivamente en la documentación del catálogo de «Pasajeros a Indias» Calderón Berrocal, 1995. Ver también una biografia de Alonso Ramírez de Vergara en Barnadas, 2002, vol. 2, pp. 674-675. La primera reseña más extensa de la vida del autor de las Noticias políticas se la debemos a Barnadas, 2003, pp. 9-14.

11 Título de bachiller en Cánones por la Universidad de San Marcos de Lima. Lima, 9.12.1606. Barnadas piensa que probablemente obtuviera también la licenciatura. Barnadas, 2003, pp. 10 y 56-57.

${ }^{12}$ Le pudieron ordenar el obispo de Santiago, Juan Pérez de Espinosa (1600-1622) o el de la Concepción, Reginaldo de Lizárraga (1598-1609). Barnadas, 2003, p. 11. 
En 1607 estaba de regreso en La Plata. Tan solo cinco años después, en $1611, \log r o ́$ de nuevo un puesto de confianza al lado de otro prelado de Charcas, su primer arzobispo ${ }^{13}$, el criollo arequipeño Alonso de Peralta ${ }^{14}$. Durante el gobierno de los dos siguientes arzobispos ocupó diversos curatos de indios en la archidiócesis hasta que, en 1630, fue nombrado rector de la iglesia de la catedral ${ }^{15}$. Finalmente, ese mismo año, el cabildo eclesiástico lo nombró provisor y vicario general de la diócesis durante la sede vacante previa a la llegada del arzobispo Borja ${ }^{16}$. Este último, que fue promovido en 1635 a la sede de La Plata, impresionado por las cualidades de Pedro Ramírez del Águila, lo tomó también a su servicio ${ }^{17}$. Fue precisamente este prelado quien, según se mencionó anteriormente, le encomendó la redacción de las Noticias políticas, crónica paralela a la que elaborara, también por encargo del arzobispo, el canónigo criollo Antonio de Herrera y Toledo ${ }^{18}$.

Nuestro protagonista falleció alrededor de 1640 en la ciudad de La Plata, después de haber residido en Charcas durante más de cuarenta años, únicamente interrumpidos por sus ya aludidos viajes a Lima y Chile. Aunque las Noticias no aportan apenas información biográfica sobre el autor, sí

13 Fue erigida archidiócesis por bula de PauloV, en la que también se estipulaba que sus territorios estarían constituidos por las diócesis de La Plata, La Paz, Tucumán, Santa Cruz de la Sierra y Asunción, que habían dependido hasta entonces de la archidiócesis de Lima.Ver Armas Medina, 1965, pp. 673-686 y Latasa, 1997, pp. 174-177.

El autor de las Noticias políticas explicaba que la propuesta de división en tres diócesis y erección del arzobispado había partido de Alonso Ramírez de Vergara. Dedica al tema la tercera noticia de la segunda digresión. Ramírez del Águila, Noticias políticas, pp. $112-114$

14 Ver una biografia en Barnadas, 2002, vol. 2, p. 509.

15 Fue designado doctrinero de Pukuwata, en la provincia de Chayanta. A ese cargo se añadió el de vicario foráneo de Charcas. Se trasladó después a la doctrina de Takupampa, donde estaba en marzo de 1629.

${ }_{16}$ En 1630, tras el fallecimiento de Francisco Sotomayor, nombrado dos años antes para el arzobispado, que no llegó a ocuparlo.

También, en 1619 el cabildo eclesiástico de Charcas había destacado que era «digno y benemérito por sus buenas partes de cualquiera de las prebendas de las iglesias catedrales de este reino». Barnadas, 2003, p. 16. p. 361 .

17 Fue consagrado obispo en La Paz, en 1637. Biografia en Barnadas, 2002, vol. 1,

18 Publicada por Barnadas: Herrera y Toledo, Relación eclesiástica. El arzobispo Borja refería así los hechos: «al punto que recibí la real cédula dispuse que dos prebendados de esta iglesia cuidasen de poner en ejecución lo que vuestra majestad manda». Carta del arzobispo Borja al rey. La Plata, 3.03.1638. AGI, Charcas, p. 135. 
permiten aproximarse a su modo de entender y ver la tierra en la que pasó la mayor parte de su vida y de la que hizo su nueva patria. En este sentido, es posible hablar de Ramírez del Águila como un autor que asume en su relato algunas de las reivindicaciones del naciente discurso criollista.

No es casualidad que la redacción de la obra que nos ocupa coincida temporalmente con la aparición en el virreinato del Perú de una incipiente «literatura criolla» que habría emergido a partir de 1620-1630 y utilizado los géneros en boga: crónicas conventuales, tratados jurídicos, etc. Este fenómeno pionero, estudiado por Lavallé, tuvo la característica de ser eminentemente limeño, en la medida que abordó sistemáticamente la exaltación de la capital del virreinato y fue obra de personas vinculadas con la Ciudad de Los Reyes. Se trataba de salir al paso del desdén de los europeos hacia el Nuevo Mundo, ensalzando la parte más europea de la capital virreinal como imagen de la lejana España ${ }^{19}$. Por contraste, las otras ciudades del virreinato solo aparecían mencionadas de forma superficial y meramente indicativa. Tanto es así que, según señala este autor, las descripciones exaltadas de Lima y sus esplendores llegaron a ser un lugar común en la mayor parte de las obras peruanas de la época y hasta la segunda mitad del XVIII no comenzó a forjarse en el virreinato del Perú una literatura de exaltación local, paradójicamente de origen limeño, en ciudades como Trujillo, Arequipa y $\mathrm{Cuzco}^{20}$.

Entre estas descripciones de la Ciudad de Los Reyes ${ }^{21}$, Guibovich ha estudiado aquellas que se insertaron dentro de un género de gran difusión en el XVII hispánico: el de la literatura corográfica. A él pertenecieron la obra del jesuita Bernabé Cobo, que permaneció inédita, y la del franciscano Buenaventura de Salinas y Córdoba, publicada en Lima en 1630. Esta última, que probablemente contó con el respaldo del cabildo de la Ciudad de Los Reyes, pretendió ser una historia de la capital virreinal semejante a las que en esos años se escribían sobre las villas peninsulares. Resalta este autor, que solo en esta Historia de Lima es posible rastrear la presencia de un incipiente discurso criollo, que habría tenido un fuerte impacto en la cronística

\footnotetext{
19 Recientemente Osorio ha insistido en la importancia que tuvo en el Barroco la construcción de la capitalidad cultural, política y comercial de Lima.Ver Osorio, 2008.

20 Lavallé, 1993b, pp. 132-134 y 139-141.

21 Recientemente Mazzotti ha contribuido a ampliar nuestro conocimiento de esta literatura con un estudio de la Fundación y grandezas de Lima, poema épico del jesuita limeño Rodrigo de Valdés, publicado por primera vez en 1687. Mazzotti, 2009.
} 
peruana colonial, debido a la amplia recepción de la obra ${ }^{22}$. Si esto es así, no parece aventurado suponer que su influencia llegó también al Alto Perú. Un reciente y preliminar trabajo de Inch, que confirma la rapidez con la que desde la capital virreinal los libros se distribuían en los atractivos mercados de Potosí y La Plata, nos permite apuntar en esta dirección ${ }^{23}$.

En definitiva, sin perder de vista el ya mencionado encargo que generó la redacción de la Noticias políticas, proponemos que en la elaboración de esta relación descriptiva, de carácter histórico y geográfico, su autor trató de emular el incipiente criollismo limeño desde la capital de la provincia más importante del virreinato. Así, la exaltación de la ciudad de La Plata, además de seguir las pautas del género corográfico, vendría a ser la primera muestra de este naciente discurso criollo regional, que en ese momento no tuvo parangón en el territorio del virreinato. Con el fin de confirmar esta hipótesis, se analizarán las convenciones del género corográfico y las posibles reivindicaciones criollistas presentes en las Noticias politicas.

\section{«NOTICIAS» Y COROGRAFÍA}

En la corografía castellana que se desarrolló en España a partir de la segunda mitad del siglo XVI, estudiada por Kagan, cabe destacar la obra sobre la ciudad de Toledo de Pedro de Alcocer, publicada en 1554, que fue modelo de muchas otras posteriores. En ella aparecen ya convencionalismos del género que se repetirán en adelante de forma sistemática ${ }^{24}$.

Los autores de la mayor parte de estas obras eran eruditos locales ${ }^{25}$, perfil que, según se ha visto, podría aplicarse a Ramírez del Águila a pesar de que no era originario de Charcas. Kagan ya destacó que el redactor de las Noticias políticas era un residente «desbordante de orgullo local», que elaboró un relato de fines cívicos pero con carácter épico, en el que se exaltaban la ciudad de La Plata y sus gentes. Según este autor, la vista panorámica que ilustraba la obra era una proyección idealizada de la ciudad de La Plata con

22 Esta influencia se aprecia, por ejemplo, en un autor tan cercano como Calancha. Guibovich, 1999, pp. 57-64.

23 Agradezco a Marcela Inch su orientación en este punto.Ver Inch, 2008, p. 505.

${ }^{24}$ Kagan, 1996, pp. 81-85. Guibovich, 1999, pp. 57-64, aplica estos convencionalismos a la literatura corográfica limeña.

25 Kagan, 1996, p. 87. 
la que Ramírez del Águila pretendía demostrar el carácter cortesano de la ciudad, un reflejo de Madrid en lo temporal y político y una «repetida Roma» en lo eclesiástico: «por ser la corte de estas provincias, que llamaré grande en las formalidades de tal, aunque mediana en lo natural de su población y edificios» ${ }^{26}$.

Una de las convenciones del género era la defensa de la historia particular, entendida como oposición a la historia general de la monarquía. Aunque Kagan entiende que el texto corográfico no era propiamente historia sino alabanza patriótica ${ }^{27}$, el autor de las Noticias políticas reivindicaba el carácter histórico de su obra hasta el punto de afirmar que se proponía enmendar otras relaciones descriptivas que había leído, «donde sus autores se han engañado mucho en referir cosas impropias a los sujetos de que han tratado, que no solo causarán su descrédito sino risa a los que las vemos y palpamos». Según Ramírez del Águila, estas inexactitudes se debían basar en «noticias apócrifas» en lugar de utilizar, como él había hecho, testigos de primera mano e información contrastada en los archivos ${ }^{28}$. El autor de las Noticias políticas reiteradamente insistía en que había tratado de proceder como «buen historiador», abordando los asuntos con imparcialidad ${ }^{29}$, sin caer en la adulación hacia los gobernantes y la tierra, propias de algunas historias particulares. Para ello había combinado la historia, la crónica, la genealogía y la geografia $^{30}$, con un estilo llano de gusto ciceroniano, eludiendo "circunvenciones oscuras» $\mathrm{y}$ «prolegómenos cultos» que tan de moda estaban:

que los galantes ingenios de este tiempo, con no pequeña injuria a la nativa pureza de nuestra lengua española, ostentan en peregrinos paráfrasis, preposterados periodos y brillantes discursos no ajustados ni convenientes a la autoridad y gravedad de sus escritos, especialmente a los de la Historia ${ }^{31}$.

26 Ramírez del Águila, Noticias políticas, p. 12. Kagan y Marías Franco, 1998, pp. 230232.

27 Kagan, 1996, p. 88.

28 En otro lugar afirmaba: «básteme la verdad con que he escrito estas noticias y los testigos que doy de su abono, cuando no se me creyera, la certificación que hago de todo, lo que digo lo testifico de primera vista». Ramírez del Águila, Noticias políticas, pp. 12 y 184.

29 Ramírez del Águila, Noticias políticas, p. 183.

30 El autor afirmaba seguir así los consejos de Abraham Ortelius en su Theatri Orbis: Ramírez del Águila, Noticias políticas, pp. 10-11.

31 Ramírez del Águila, Noticias políticas, pp. 9-12. 
Ramírez del Águila dejaba además constancia de su respeto por una serie de cronistas de Indias ${ }^{32}$, entre los que destacaba a Juan de Solórzano Pereira con su recién aparecida Política Indiana, obra que por su rigor histórico merecía sus máximos elogios ${ }^{33}$ :

comprende con sus pruebas evidentes, estilo elegantísimo, brevedad moderna y concisión de discursos, todo lo que los demás han dicho, de manera que visto, no hay más que ver y de las materias que trata y su médula se pueden hacer muchos volúmenes de historia gustosísimos (...). Léase con atención y se verá la riqueza que tiene de escritura, derechos, pruebas e historia: juzgo que dijo todo lo que hay que decir de las Indias y que no dejó nada intacto ${ }^{34}$.

Ramírez del Águila reconocía sentirse abrumado tras haber leído a Solórzano y enviar «con vergüenza» sus Noticias, «mal limadas y peor dispuestas». Las había redactado con prisa para que salieran en la Armada de ese año y las remitía "como las dispuse, en borrón de mi mala letra», confiando en que Tamayo de Vargas se encargaría de encuadernarlas, corregirlas y enmendarlas antes de presentarlas a los consejeros ${ }^{35}$. Al menos, había cumplido con el encargo de redactar una historia particular, con el fin de mostrar «la bondad de esta tierra y estado de las cosas de esta ciudad y provincia». Además, entendía que la historia local no debía escribirse más que de una metrópoli, reino o gran provincia, como era el caso de Charcas, «metrópoli de estas provincias y de varones ilustres, así eclesiásticos como seculares, que han conquistado tan opulentos reinos como estos y que los

32 La lista que proporcionaba es un tanto arbitraria, aparecen en ella autores importantes, mezclados con otros poco conocidos o que no eran propiamente cronistas. Mencionaba, entre otros, a Hernán Cortés, Gonzalo Fernández de Oviedo, Álvar Núñez Cabeza de Vaca, fray Marcos de Niza, Américo Vespucio, Francisco de Jerez, Francisco López de Gómara, Francisco Vázquez, Antonio de Mendoza, Bartolomé de Las Casas, José de Acosta, Antonio de Herrera y el Inca Garcilaso de la Vega. Ramírez del Águila, Noticias políticas, p. 185.

33 Se refería al primer volumen de la obra, publicado en latín en 1629, puesto que el segundo apareció el año de redacción de las Noticias y, como se ha visto, estas fueron fechadas el primero de enero. En este primer volumen se trataba el descubrimiento de los territorios indianos de la monarquía hispánica, la fundamentación de la conquista, su justicia y necesidad. Solórzano Pereira, Política Indiana, vol. 1, pp. XxIX-Xxx.

${ }^{34}$ Ramírez del Águila, Noticias políticas, p. 185.

35 En esa misma línea afirmaba: «no ignoro van más corrientes en la llaneza de amistad que dignas de llegar a su presencia». Ramírez del Águila, Noticias políticas, p. 185. 
sustentan y gobiernan con tanta gloria de hazañas y buen nombre» ${ }^{36}$. Por este motivo, se mostraba sorprendido de que nadie antes que él hubiera tratado la historia de aquel territorio, a pesar de ser un lugar tan emblemático en el conjunto de los reinos hispanos: «Muchos han escrito de conquistas, fastos y anales de estos reinos pero ninguno de estas provincias, que es la nata de ellos» 37 .

La estructura de la obra de Pedro Ramírez del Águila reflejaba también las convenciones del género corográfico. Las Noticias estaban divididas en tres partes o "disgresiones», que contaban a su vez cada una con seis "noticias». Dentro de esta división tripartita, la primera se dedicaba a la fundación y emplazamiento de la ciudad, la segunda parte a su «buen gobierno» y la tercera a su condición de "civitas cristiana», ciudad en la que la Iglesia había alcanzado un elevado desarrollo. Estos tres objetivos estaban también presentes en otras corografías y aparecen de forma clara, según hemos podido comprobar, en la estructura de la Historia de Lima de Buenaventura de Salinas y Córdoba, hecho que confirmaría la vinculación entre ambos textos $^{38}$.

En la primera parte, el emplazamiento de la ciudad y su territorio se describía exagerando sus cualidades, como era habitual en las corografias, y remontándose a su fundación ${ }^{39}$. Se destacaba, por ejemplo, la abundancia de agua de la región y la fertilidad del territorio, lleno de huertas con una producción abundante y variada, así como de jardines con todo tipo de flores $^{40}$. La Plata se presentaba además como cabeza de un territorio estratégico y bien comunicado, dentro del conjunto del virreinato. A la riqueza de minerales del territorio se añadía la del comercio, que permitía un excelente abastecimiento de la ciudad ${ }^{41}$. El único inconveniente que el autor reco-

36 Ramírez del Águila, Noticias políticas, p. 184.

37 Ramírez del Águila, Noticias políticas, p. 184.

38 El discurso II de la obra se titulaba: «De los méritos y excelencias de la ciudad de Lima». En el capítulo I se alababa el emplazamiento, en el II el autor se remontaba a su fundación, en el III destacaba el buen gobierno, en el iv hablaba de la Universidad, en el v se describía Lima como "civitas cristiana" y en el vi se exponían la nobleza y lustre de sus vecinos, así como el buen abastecimiento y la riqueza del comercio. Ver Salinas y Córdoba, Memorial de las historias del Nuevo Mundo; Guibovich, 1999, p. 54.

39 Kagan, 1996, pp. 84 y 89.

40 Kagan, 1996, p. 84.

41 Ramírez del Águila, Noticias políticas, pp. 30-31. En la segunda parte, se mencionaba la existencia de 30 tiendas de mercaderes importantes de «ropa de Castilla y de la 
nocía era la escasez de agua, por la falta de río, causa principal de que la población de la ciudad no hubiese crecido más ${ }^{42}$.

Por lo demás, sus habitantes vivían - de nuevo, como era habitual indicar en las corografias- con nobleza y boato ${ }^{43}$ propios de cualquier corte del Viejo Mundo, con grandes familias de muchos criados, lujosos vestidos ${ }^{44}$, señoriales mansiones y ricas vajillas de oro y plata, etc. ${ }^{45}$. Concluía el autor señalando que

todo lo que toca al lustre de casas, trajes, galas, caballeros, caballos, jaeces, libreas, lacayos, pajes, festines y regalos lo hay en esta ciudad en el grado que en las de muy gran parte de España ${ }^{46}$.

En la segunda parte pasaba a referirse a «lo tocante y perteneciente al gobierno político y real de la ciudad» y, una vez más, la relación seguía las convenciones del género. Una de ellas era la de la lealtad a la Coron ${ }^{47}$. En este caso, el autor resaltaba la fidelidad de La Plata a pesar de no ser una ciudad defendida por muralla ni armas, estar alejada de un rey «tan distante de sus ojos» y haber sufrido esas provincias distintas «inquietudes y alteraciones $^{48}$.

En el gobierno temporal era obligado reconocer la prioridad de Lima, por ser la capital y lugar donde residía el virrey pero, inmediatamente después, Pedro Ramírez del Águila situaba a La Plata, por depender de ella el

tierra» y alrededor de 100 pulperías, donde se vendían pan y vino y cosas de comer. Había además muchas «tiendas» de todos los oficios, la mayoría ejercidos por indígenas. Ramírez del Águila, Noticias políticas, p. 106.

42 Ramírez del Águila, Noticias políticas, pp. 60-61.

43 Kagan, 1996, p. 89.

44 «cuyo traje ordinario de la gente principal es el más galán, más costoso y cortesano que usa en las cortes de Europa. Toda la gente noble, cortesana y de plaza viste de negro, terciopelos, damascos y las mejores telas que se tejen en Granada y Toledo». Ramírez del Águila, Noticias políticas, p. 56.

45 «Toda la más gente de esta ciudad y provincia, aun la ordinaria española, come en platos de plata y se sirven de muy buenas vajillas y esto es tan ordinario acá como en España la loza de Talavera, y así las de la gente rica y principal son muy copiosas y ricas de fuentes, aguamaniles y otros vasos de oro y plata». Ramírez del Águila, Noticias políticas, p. 58 .

46 Ramírez del Águila, Noticias políticas, p. 59.

47 Kagan, 1996, p. 84

48 Ramírez del Águila, Noticias políticas, pp. 102, 136-143. 
mantenimiento del resto de las ciudades del virreinato, a las que continuamente enviaba su plata de modo que: «Para sustentarse no había menester a ninguna de las demás y todas la han menester a ella, por ser el erario y cabeza del que las enriquece y les envía plata y reales» ${ }^{49}$. También señalaba su superioridad con respecto al Cuzco, enmendando en este punto a Solórzano debido a lo que había crecido en los últimos años ${ }^{50}$.

Otra convención corográfica era la enumeración de las instituciones de gobierno $^{51}$. De nuevo, La Plata se situaba en segundo lugar pues los oficios reales y eclesiásticos «exceden a todas las [ciudades] del Pirú en rentas, estimación y autoridad, excepto las de Lima» ${ }^{52}$. La ciudad y su territorio estaban bajo la jurisdicción de la audiencia de Charcas junto con las extensas gobernaciones de Santa Cruz, Tucumán, Buenos Aires y Paraguay. Ramírez del Águila destacaba que bajo la responsabilidad de su presidente estaba la difícil tarea de despachar la plata del rey para llevarla anualmente en la Armada ${ }^{53}$.

Tras mencionar otros tribunales asentados en la ciudad, se refería al cabildo secular y reconocía que la elección de los alcaldes ordinarios solía ser «muy ruidosa». Describía las «ilustres» casas del ayuntamiento y su cárcel y concluía que el gobierno de La Plata era "muy cristiano y político», a pesar de ser tierra de "gente ociosa» donde se cometían delitos graves, que la mayor parte de las veces eran justamente castigados ${ }^{54}$.

Ramírez del Águila enumeraba los pueblos y ciudades de españoles ${ }^{55}$, así como los corregimientos de indios del territorio ${ }^{56}$. Con especial hincapié se refería al buen gobierno de los indígenas. Explicaba que, considerado

49 «Esta ciudad por autoridad, puesto y lugar es la segunda de estos reinos y la primera después de la de Los Reyes o Lima, donde asiste el virrey». Ramírez del Águila, Noticias políticas, p. 103.

50 Solórzano Pereira, 1972, lib. 1, cap. 6, n. 55. Ramírez del Águila, Noticias políticas, p. 103: «cabeza fue aquella de estos reinos en tiempos de los ingas, pero ya en el de los gloriosos Filipos, esta lo es de estas provincias».

51 Kagan, 1996, p. 84.

52 Ramírez del Águila, Noticias políticas, p. 103.

53 Ramírez del Águila, Noticias políticas, p. 104.

54 Ramírez del Águila, Noticias políticas, pp. 104-106.

Sobre las tensiones entre esta institución local y la audiencia como consecuencia del intervencionismo de la primera en las residencias y en elecciones municipales Bridikhina, 2007, pp. 64-67.

55 Ramírez del Águila, Noticias políticas, pp. 108-112.

56 Ramírez del Águila, Noticias políticas, pp. 116-122. 
de forma general, se podía calificar de «bueno, político y cristiano», tanto por ser ellos reducibles a razón, policía y justicia, como por estar bien arbitrado a través de sus cabildos. A pesar de ello, denunciaba los abusos de que eran objeto por parte de los corregidores, aunque hacía notar que no eran los únicos, ya que los indígenas sufrían también extorsiones por parte de sus curacas:

tienen los indios otro sobrehueso no pequeño que es el de sus gobernadores indios, a estos, como a sus señores naturales, los temen, obedecen y respetan con grande extremo y ellos los mandan con tanta soberbia que están temblando delante de ellos y no obedecen con tanto miedo a los corregidores como a sus caciques y principales, cuyo mandato tuerto o derecho lo han de cumplir como si fuera divino ${ }^{57}$.

No dejaba el autor de hacer referencia al principal problema del altiplano, la disminución de la población indígena, ni de señalar a las minas de Potosí como la principal causa de ella. Esta denuncia podría estar relacionada con la que ya había hecho también en su momento Salinas y Córdoba ${ }^{58}$. El descenso demográfico de este grupo vendría también favorecido, según Ramírez del Águila, por el proceso de españolización de los indígenas, especialmente intenso entre los curacas, que habían asimilado el modo de vivir nobiliario de la península:

son ya todos muy ladinos, visten a lo español y ciñen espada y la mayoría son ricos y viven con ostentación y lustre [...] son muy amigos de ser don y así le tienen y se le llaman con sobrenombres y alcuñas ${ }^{59}$ de españoles como Mendoza, Guzmanes Velascos y otros ${ }^{60}$.

El resumen de las ideas principales contenidas en esta segunda parte de las Noticias puede cerrarse con la recomendación que el autor hacía acerca de la conveniencia de realizar una nueva visita general del virreinato, semejante a la llevada a cabo por Francisco de Toledo, que tan beneficiosa había sido para el territorio charqueño:

57 Ramírez del Águila, Noticias políticas, pp. 123-125.

58 En el discurso III se dedicaba a tratar este tema pormenorizadamente. Ver Salinas y Córdoba, Memorial de las historias del Nuevo Mundo.

59 Alcuña, alcurnia (Cov.).

${ }^{60}$ Ramírez del Águila, Noticias políticas, pp. 123-125. 
importantísima para el aumento de las ciudades, premio de los beneméritos, castigo de los delincuentes, reedificación de poblaciones y caminos y otros buenos efectos que no tienen por la falta de su presencia ${ }^{61}$.

Finalmente, en la tercera parte de la obra se exponían las excelencias de La Plata como centro religioso, siguiendo de nuevo las convenciones corográficas ${ }^{62}$. Pedro Ramírez del Águila describía con precisión las grandezas de la diócesis, por ser este el objetivo principal de su relación -según lo dispuesto en la mencionada cédula de 1635- y porque era sin duda el aspecto que mejor conocía tras haber colaborado directamente con tres de sus obispos y haber desempeñado diferentes oficios de cura de almas en el territorio. Si para el gobierno temporal se había tenido que plegar ante la superioridad de la capital virreinal, ahora se atrevía a afirmar que, aunque la archidiócesis de La Plata no era tan antigua como la de Lima, la igualaba en "ornato, celebración de oficios y culto divino» ${ }^{63}$.

La cercanía con la diócesis se percibe tanto en el vivo retrato que incorporaba de algunos de sus prelados, como en las noticias directas que daba sobre la celebración de sínodos. Especial atención dedicaba el autor al cabildo eclesiástico que, según señalaba, había estado siempre compuesto por personas "de mucha autoridad, gravedad e importancia» ${ }^{64}$. Pero tal vez lo más significativo fuera su encendida defensa de los curas de indios, de quienes afirmaba que en general cumplían bien su ministerio y eran auténticos "padres» de los indígenas ${ }^{65}$. Por su parte, estos últimos destacaban por su piedad y cuidado del culto, hasta el punto de estar sus parroquias mucho mejor dotadas de plata, ornamentos, música y servicio que las de los españoles.

\section{DisCURSO CRIOLLISTA}

Tras analizar la presencia en las Noticias, de elementos propios de la literatura corográfica, pasamos a abordar la introducción de las reivindicacio-

61 Ramírez del Águila, Noticias políticas, p. 122.

${ }^{62}$ Kagan, 1996, p. 84

63 Ramírez del Águila, Noticias políticas, p. 144.

64 También mencionaba los concilios provinciales. Ramírez del Águila, Noticias políticas, pp. 162-163, 170-171.

65 Ramírez del Águila, Noticias políticas, pp. 160-161. 
nes de un emergente discurso criollo regional nacido para combatir el desdén europeo hacia el Nuevo Mundo.

En ese contexto, es significativa la crítica que Ramírez del Águila hacía de la representación alegórica de América como una mujer indígena desnuda ${ }^{66}$, generalizada ya en este momento, y su propuesta de representarla vestida y adornada de joyas en atención a su pasado indígena y a su riqueza:

...desluciendo mucho la nobleza de esta América figurándola una mujer desnuda y bárbara en alusión de aquellos indios bárbaros, desnudos, que se hallaron en algunas islas de poca importancia, tomando lo menos que accesorio por principal, siendo así que lo no visto de estos reinos era gente guerreadora, política, rica de oro y plata, piedras preciosas y perlas y bien vestida con que se debía figurar y significar esta América en una mujer muy hermosa, bien vestida y cargada de riquezas, de armas, de joyas $y$ piedras preciosas, que esto era darle los trofeos que merece ${ }^{67}$.

Detrás de esta propuesta iconográfica estaría la demanda de reconocer que América era la abastecedora de metales preciosos de Castilla y, como consecuencia de ello, una parte fundamental de la monarquía hispánica. Ramírez del Águila reflejaba así un modo de representar el Perú como mantenedor de la política exterior española que, según han señalado Périssat y Zugasti, ya se había generalizado en las representaciones festivas del virreinato $^{68}$.

El desprecio europeo por lo americano parece estar también detrás de la idealizada visión que el autor ofrecía de los criollos, cuyas cualidades estarían favorecidas por «la benignidad de los astros, que en esta parte influyen» ${ }^{69}$. Así, los varones eran descritos como: «aptos para todo género de ciencias y artes, afables, nobles, dóciles, de ánimo varonil y constante, valientes esforzados para las armas etc.» ${ }^{70}$. Por su parte, las criollas, además de ser «en general hermosas, limpias, aseadas, graciosas y discretas» vestían con lujo y a la última moda:

66 Sobre las distintas manifestaciones de esta iconografia ver Zugasti, 2005.

67 La cursiva es propia. Ramírez del Águila, Noticias políticas, p. 184.

68 Périssat, 2002, pp. 228-231, Zugasti, 2005, pp. 99-119.

69 Ramírez del Águila, Noticias políticas, p. 54.

70 Para salir al paso de esta carencia y dar a conocer los logros de los habitantes del lugar, introducía en esta parte de su crónica un epígrafe: «De los varones insignes que ha habido en esta ciudad así naturales como forenses». Ramírez del Águila, Noticias políticas, p. 54 . 
pues no hay alguna que no quiera imitar a una reina ni hay uso que venga nuevo de la corte que no le usen y su ordinario acá es el muy extraordinario en España en gasto de lamas, telas y sedas ${ }^{71}$.

Por contraste, el autor criticaba la arrogancia y avaricia del «chapetón» que viajaba al altiplano en busca de fortuna y regresaba a España en cuanto la lograba, olvidando la gratitud debida a la tierra que lo había enriquecido:

los mismos que en ella [en Charcas] han tenido amigos, honra, aceptación y dineros y se vuelven a las suyas ricos, las van deshonrando y maldiciendo y publicando que no hay más mala tierra en el mundo ${ }^{72}$.

Desde esta perspectiva criollista debe entenderse también la incorporación por parte de Ramírez del Águila del principio de prelación por el que los criollos debían ser, según se reconocía en las Leyes de Indias, los primeros beneficiarios de rentas y oficios de la tierra ${ }^{73}$. Así, al tratar la fundación de la ciudad, el autor rememoraba los méritos de los conquistadores y primeros pobladores de La Plata, germen de una nobleza de la tierra «nervio principal del lustre y el ornato de la ciudad", que se encontraba en ese momento empobrecida hasta el punto de quedar solo quince encomenderos de escasa renta. El autor demandaba que se rehabilitara a este grupo mediante la concesión de oficios, encomiendas y hábitos militares ${ }^{74}$.

Por último, cabe destacar que en el discurso criollo de Ramírez del Águila latía una constante comparación con la capital virreinal en la que muchas veces La Plata se situaba al mismo nivel que Lima.Ya se ha mencionado, por ejemplo, cómo la ciudad se equiparaba a cualquiera del Viejo Mundo en lo referente al modo de vida cortesano. También se aludió a la demanda de una posición de igualdad entre las dos archidiócesis sudamericanas que hacía el autor de las Noticias. En esta línea, no podía quedar al margen de la crónica estudiada el litigio universitario que se planteó entre las dos ciudades en el siglo XVII y que quedó, por ejemplo, reflejado en el famoso dictamen escrito en 1625 por el criollo limeño Antonio de León Pinelo, en defensa de la Universidad de San Marcos frente a las aspiraciones

71 Ramírez del Águila, Noticias políticas, pp. 54-56.

72 Ramírez del Águila, Noticias políticas, pp. 157-158.

73 Lavallé, 1993a, pp. 29-35, 42.

74 Ramírez del Águila, Noticias políticas, pp. 68-69. 
de la de La Plata ${ }^{75}$. Por eso, cuando en 1639 Pedro Ramírez del Águila redactaba sus Noticias, manifestaba su satisfacción por el reciente establecimiento de una Universidad en La Plata ${ }^{76}$, aunque lamentaba que no se hubieran implantado todavía los grados de Cánones, Leyes y Medicina con el fin de eludir las dificultades derivadas de la estancia en Lima ${ }^{77}$. El autor no dejaba pasar la ocasión para introducir una nueva crítica a la capital virreinal, referida en este caso a su clima. Llegaba a afirmar que resultaba tan insalubre para los criollos de Charcas que muchos enfermaban y morían allí:

de donde vuelven muy pocos de los que han ido por la enfermedad de aquella tierra y riesgo que corre la salud de los criollos de esta ciudad en ella, que todos los más se mueren ${ }^{78}$.

La indudable exageración introducida en este punto por Ramírez del Águila reflejaba, una vez más, una imperiosa necesidad de ensalzar su patria de adopción situándola, en lo posible, incluso por encima de la capital virreinal.

\section{CONClusiones}

Un repaso de los convencionalismos de la literatura corográfica presentes en las Noticias políticas de Pedro Ramírez del Águila nos permite concluir que estamos ante un texto con el que el autor, charqueño de adopción, reivindicaba el poder económico, político y cultural de la ciudad de La Plata y Charcas tanto en el ámbito virreinal -frente a la sombra de la capital limeña- como en el de la monarquía hispánica, destacando el lugar principal que se le debía otorgar, según él con toda justicia, entre las ciudades que componían los reinos hispanos. Aunque el autor no era criollo de nacimiento, lo era de adopción y se incorporaba así a un emergente discur-

75 León Pinelo, Por la real Universidad.

76 Ver el estudio de González Rodríguez, 1994.

77 «El cielo y aires de esta ciudad son limpísimos y puros, principio y causa de conservarse aquí la salud sin rigurosos achaques, libre de pestes y otros contagios, con que muchos así naturales como forenses, llegan a la suma senectud de más de cien años». Ramírez del Águila, Noticias políticas, pp. 29 y 155.

78 Ramírez del Águila, Noticias políticas, pp. 154-155. 
so criollo reivindicador del lugar que los españoles americanos y las tierras del Nuevo Mundo ocupaban por derecho en el contexto de la monarquía.

\section{BiBLIOGRAFÍA}

Armas Medina, F. de, «La jerarquía eclesiástica peruana en la primera mitad del siglo XVII", Anuario de estudios americanos, 22, 1965, pp. 673-703.

Barnadas, J. M., Diccionario histórico de Bolivia, Sucre, Grupo de Estudios Históricos, 2002.

- El presbitero y cronista Pedro Ramírez del Águila: aporte a su biografía y a su obra, 15961640, Sucre, Archivo-Biblioteca Arquidiocesanos Monseñor Taborga, 2003.

BRIDIKHINA, E., Theatrum mundi: entramados del poder en Charcas colonial, Lima, IFEA, 2007.

Calderón Berrocal, M. del C., «Un extremeño ilustre: Alonso Ramírez de Vergara, obispo de Charcas», en XXIV Coloquios Históricos de Extremadura, 1995, $<$ http://www.chde.org/index.php?option $=$ com_content\&view $=$ article\&id $=6$ 35:un-extremeno-ilustre-alonso-ramirez-de-vergara-obispo-decharcas\&catid $=41: 1995 \&$ Itemid $=58>$.

Covarrubias, S. de, Tesoro de la lengua castellana o española, ed. I. Arellano y R. Zafra, Madrid/Frankfurt, Iberoamericana/Vervuert, 2006.

Cuesta Domingo, M., «Los cronistas oficiales de Indias. De López de Velasco a Céspedes del Castillo», Revista Complutense de Historia de América, 33, 2007, pp. 115-150.

Esteve Barba, F., Historiografía indiana, Madrid, Gredos, 1992.

González Dávila, G., Teatro eclesiástico de la primitiva iglesia de las Indias Occidentales, vidas de sus arzobispos y obispos, y cosas memorables de sus sedes, ed. J. Paniagua Pérez y M. I.Viforcos Marinas, León, Universidad de León, 2001-2004, 2 vols.

GonzÁlez Rodríguez, M. de la P., «La Universidad de San Francisco Xavier de Chuquisaca (Alto Perú). Bibliografia crítica y estado de la cuestión», Estudios de Historia Social y Económica de América, 1994, 11, pp. 181-188.

Guibovich, P., «Cultura y élites: las historias sobre Lima en el siglo XVII», en Beneméritos, aristócratas y empresarios: identidades y estructuras sociales de las capas altas urbanas en América hispánica, Madrid/Frankfurt, Iberoamericana/Vervuert, 1999, pp. 53-65.

Herrera y Toledo, A. de, Relación eclesiástica de la Santa Iglesia Metropolitana de los Charcas: 1639, ed. Josep M. Barnadas, Sucre, Archivo-Biblioteca Arquidiocesanos «Monseñor Taborga», 1996.

Inch, M., «Libros, comerciantes y libreros: La Plata y Potosí en el siglo de oro», en La construcción de lo urbano en Potosí y La Plata: siglos XVI-XVII, La Paz, Archivo y Biblioteca Nacionales, 2008, pp. 417-503. 
KAGAN, R. L., «La corografía en la Castilla moderna: género, historia, nación», en Studia aurea: actas del III Congreso de la AISO (Toulouse, 1993), Pamplona, GRISO/LEMSO, 1996, pp. 79-92.

- y F. Marías Franco, Imágenes urbanas del mundo hispánico, 1493-1780, Bilbao, Iberdrola, 1998.

Latasa, P., Administración virreinal en el Perú: gobierno del marqués de Montesclaros (1607-1615), Madrid, Centro de Estudios Ramón Areces, 1997.

LAVALlÉ, B., «Del espíritu colonial a la reivindicación criolla», en Las promesas ambiguas: ensayos sobre el criollismo colonial en los Andes, Lima, Pontificia Universidad Católica del Perú/Instituto Riva-Agüero, 1993a, pp. 23-43.

— «Exaltación de Lima y afirmación criolla en el siglo XVII», en Las promesas ambiguas: ensayos sobre el criollismo colonial en los Andes, Lima, Pontificia Universidad Católica del Perú/Instituto Riva-Agüero, 1993b, pp. 129-141.

Mazzotti, J. A., «Épica barroca y esplendor limeño en el siglo Xvir: Rodrigo de Valdés y los límites del nacionalismo criollo», en Los límites del océano: estudios filológicos de crónica y épica en el Nuevo Mundo, Bellaterra, Centro para la Edición de los Clásicos Españoles, 2009, pp. 135-173.

Mesa, J. D. y T. Gisbert, «La capilla funeraria del obispo Ramírez de Vergara en la catedral de Sucre», Arte y arqueología, 2, 1972, pp. 109-116.

Osorio, A., Inventing Lima: Baroque Modernity in Peru's South Sea Metropolis, New York, Palgrave Macmillan, 2008.

PéRISSAT, K., Lima fête ses rois (XVIe-XVIIIe siècles): hispanité et américanité dans les cérémonies royales, Paris, L'Harmattan, 2002.

León Pinelo, A. de, Por la real Universidad y escuelas generales de S. Marcos de la ciudad de Lima, en las provincias del Perú. Con el arzobispo, deán y cabildo de la santa iglesia de la ciudad de La Plata, y cabildos seculares della, y de la villa de Potosí, en la provincia de los Charcas, 1625.

Ramírez del Águila, P., Noticias políticas de Indias y relación descriptiva de la ciudad de La Plata, metrópoli de las provincias de los Charcas y Nuevo Reino de Toledo, en las occidentales del gran imperio del Perú..., ed. J. Urioste Arana, Sucre, División de Extensión Universitaria, 1978.

SAlinas y Córdoba, B. de, Memorial de las historias del Nuevo Mundo Pirú: méritos, y excelencias de la ciudad de los Reyes, Lima..., Madrid, Fundación Histórica Tavera/ Digibis, 2000.

Solórzano Pereira, J. de, Política Indiana, ed. M. Á. Ochoa Brun, Madrid, Atlas, 1972.

Zugasti, M., La alegoría de América en el Barroco hispánico: del arte efímero al teatro, Valencia, Pre-Textos, 2005. 